\title{
Prenatal diagnosis of fetal skeletal dysplasia using 3-dimensional computed tomography: a prospective study
}

\author{
Miyoko Waratani* ${ }^{*}$, Fumitake Ito, Yukiko Tanaka, Aki Mabuchi, Taisuke Mori and Jo Kitawaki
}

\begin{abstract}
Background: Fetal skeletal dysplasia (FSD) comprises a complex group of systemic bone and cartilage disorders. Many FSD phenotypes have indistinct definitions, making definitive prenatal diagnosis difficult. The condition is typically diagnosed using sonography; however, three-dimensional computed tomography (3D-CT) also aids in making a prenatal diagnosis. This study aimed to examine the efficacy of 3D-CT in the prenatal diagnosis of FSD by comparing the diagnostic accuracy of fetal sonography and 3D-CT.

Methods: On suspicion of FSD based on ultrasound examination, we performed 3D-CT prenatally to obtain detailed skeletal information on FSD. To minimize exposure of the fetuses to radiation without compromising image quality, we used predetermined 3D-CT settings for volume acquisition.
\end{abstract}

Results: Nineteen fetuses were suspected of having skeletal dysplasia based on ultrasonography findings. Of these, 17 were diagnosed with FSD using 3D-CT. All 17 fetuses diagnosed with FSD prenatally were confirmed postnatally to have the condition. The postnatal diagnosis (campomelic dysplasia) differed from the prenatal diagnosis (osteogenesis imperfecta) in only one infant. Sixteen cases (94.1\%) were diagnosed both prenatally and postnatally with FSD. Five infants had lethal skeletal dysplasia; one died in utero, and four died as neonates. We determined the appropriate delivery method for each infant based on the prenatal diagnosis.

Conclusions: $3 \mathrm{D}-\mathrm{CT}$ is a valuable tool for augmenting ultrasound examinations in the diagnosis of FSD. While improving the diagnostic tool of sonography is essential in cases of suspected FSD, 3D-CT imaging is indispensable for diagnosis and classification, enabling better planning for resuscitation of the infant after birth.

Trial registration: University Hospital Medical Information Network (UMIN) Center trial registration number is UMIN000034744. Registered 1 October, 2018 - Retrospectively registered.

Keywords: Fetal skeletal dysplasia, Fetal diagnosis, 3D-CT, Shortening of long bones, Gene expression

\section{Background}

Fetal skeletal dysplasia (FSD) is a group of systemic bone and cartilage disorders that develops prenatally and may be detected by fetal ultrasonography. Considering most cases of skeletal dysplasia involve the mutation of a single gene, a postnatal diagnosis can be reached if this

\footnotetext{
* Correspondence: mwara@koto.kpu-m.ac.jp
}

Department of Obstetrics and Gynecology, Kyoto Prefectural University of Medicine, 645 Kaijii-cho, Kamigyo-ku, Kyoto 602-8566, Japan mutation is identified. Although the widespread use of fetal ultrasound imaging has improved the detection of FSD, prenatal diagnosis remains relatively difficult because of the rarity of the condition (approximately one in every 5000 births) [1]. The diversity of the FSD phenotypes also contributes to the difficulty in diagnosing these disorders. FSDs comprise 436 diseases that are classified into 42 groups, according to the Nosology \& Classification of Genetic Skeletal Disorders: 2015

(c) The Author(s). 2020 Open Access This article is licensed under a Creative Commons Attribution 4.0 International License, which permits use, sharing, adaptation, distribution and reproduction in any medium or format, as long as you give appropriate credit to the original author(s) and the source, provide a link to the Creative Commons licence, and indicate if changes were made. The images or other third party material in this article are included in the article's Creative Commons licence, unless indicated otherwise in a credit line to the material. If material is not included in the article's Creative Commons licence and your intended use is not permitted by statutory regulation or exceeds the permitted use, you will need to obtain permission directly from the copyright holder. To view a copy of this licence, visit http://creativecommons.org/licenses/by/4.0/. The Creative Commons Public Domain Dedication waiver (http://creativecommons.org/publicdomain/zero/1.0/) applies to the data made available in this article, unless otherwise stated in a credit line to the data. 
Revision [2]; however, the phenotypic definition of each disease is often unclear. It is important to clarify whether it is a lethal or nonlethal disorder to plan the most effective delivery method and the best postnatal treatment [3].

Fetal ultrasonography is the most standard method to detect FSD; however, it is unsuitable for the analysis of the skeleton because supersonic waves reflect it with the bone cortex. It was reported that the rate of accurate prenatal diagnosis of skeletal dysplasia was approximately 65\% [4]. Fetal magnetic resonance imaging (MRI) is useful for the analysis of the fetal spine and depiction of marrow and soft tissue; however, it is unsuitable for bone cortical depiction like fetal sonography. Threedimensional computed tomography (3D-CT) is commonly used to diagnose cardiac atherosclerosis, cerebral aneurysms, and cerebral artery stenosis. This imaging technique creates better images of thromboses and vascular wall calcification in cerebral aneurysms compared to cerebral angiography. In 2004, Ruano et al. reported that fetal 3D-CT was a useful diagnostic method, complementary to ultrasonography, and may improve the diagnostic accuracy of skeletal disorders [5]. Considering the increased risk associated with the radiation introduced by this clinically beneficial method, we elected to use low-dose 3D-CT for prenatal diagnosis in this study. This study aimed to determine the efficacy of 3D-CT in the prenatal diagnosis of FSD by comparing the prenatal and postnatal diagnoses in patients with this condition.

\section{Methods}

\section{Study design}

A prospective study was conducted involving pregnant women whose pregnancy/childbirth was being managed by the Department of Obstetrics and Gynecology at the Kyoto Prefectural University of Medicine during a period from 2012 to 2019. Fetuses were included in the study if they had a suspected bone abnormality based on routine ultrasound examinations. We recorded any family history of skeletal dysplasia and complications during pregnancy.

\section{Materials}

Pregnant women whose pregnancies/childbirths were managed at our hospital and who met the following selection criteria were included as participants: (1) pregnancy at age 20 years or older at the time of consent, (2) gestational age $>24$ weeks of pregnancy, (3) fetal ultrasonography showing a short femur (below the 10th percentile of fetal measurements) or an image of a fracture, curvature, or deformity in a long bone, skull, rib, or spine, (4) written informed consent to undergo 3D-CT was provided.

\section{Sonographic examination}

We used Voluson E8 and E10 ultrasound systems (General Electric Healthcare, Tokyo, Japan) to screen for associated anomalies. All operators were experts in fetal sonography who have the certification of a perinatal specialist with an experience of more than seven years. We began by measuring the fetus using a standard approach (biparietal diameter, abdominal circumference, and femur length) and identifying fetuses that displayed femur length measurements below the 10th percentile. We then recommended 3D-CT scanning if the fetal femur or any other long bones were found to be shortened, regardless of whether they were abnormally shaped, as this indicated potential FSD.

\section{Three-dimensional computed tomography}

3D-CT (Aquilion RXL; TOSHIBA, Tokyo, Japan) was only performed after thoroughly explaining the potential effects of radiation exposure to the mother and receiving informed consent from the mother. To minimize exposure of the fetus to radiation without compromising image quality, the following predetermined settings (Table 1) were used for volume acquisition.

This was low-dose 3D-CT, a median CT dose index volume $\left(\mathrm{CTDI}_{\mathrm{vol}}\right)$ of $3.5 \mathrm{mGy}$ (range: $\left.1.9-4.9 \mathrm{mGy}\right)$, that we reduced to approximately $30 \%$ of radiation doses to be required in the case of an examination for standard dose of abdominal CT. We created a maximum intensity projection (MIP) image from 3D-CT images for diagnosis, if necessary. The MIP is a method to make an X-ray image where we are able to take an image focused only on the area of main observation from 3D-CT imaging. Additional tests, such as MRI or amniotic chromosomal testing, were performed if required to determine fetal prognosis or to differentiate skeletal dysplasia from other diseases. Lethality was determined by the presence of a narrow thorax and lung hypoplasia based on ultrasonograms and MRI images.

\section{Postnatal examination}

Postnatally, we recorded the neonatal weight and length and performed an X-ray examination to verify the shape

Table 1 Protocol of 3D-CT

\begin{tabular}{ll}
\hline slice thickness (mm) & 1.0 \\
slice interval (mm) & 1.0 \\
rotation time (sec) & 0.5 \\
helical pitch & 1.438 \\
voltage (kV) & 120 \\
beam width (mm) & 16 \\
CTDI & (mGy) mean (range) \\
DLP (mGy.cm) mean (range) & $3.5(1.9-4.9)$ \\
\hline
\end{tabular}

$C_{C T D I_{\text {vol }}} \mathrm{CT}$ dose index volume, DLP dose length product 
of all bones. In the cases where genetic examination was needed, testing was performed to confirm the diagnosis after obtaining informed consent from the parents. Genomic DNA was extracted from the umbilical cord or the infant's blood.

\section{Results}

A total of 2447 fetuses underwent prenatal sonography and were delivered in our institution between 2012 and 2019. Of the 2447 fetuses, sonography revealed that 19 were suspected of having FSD, and we performed 3DCT for those 19 fetuses. Of the 19 fetuses that underwent 3D-CT, 17 were diagnosed with FSD prenatally; however, the other two cases were diagnosed as not being FSD (one of the normal fetus, and another case of suspected trisomy 21). FSD was confirmed postnatally in all 17 of these fetuses. Sonography had a sensitivity of $100 \%$, a specificity $99 \%$, and positive and negative predictive values of 89.5 and $100 \%$, respectively. On the other hand, 3D-CT had 100\% sensitivity and specificity, and additionally, positive and negative predictive values of $100 \%$.

\section{Patient characteristics}

The mean maternal age was 32.2 (range: 20-41) years, and the mean gestational age at the first findings of FSD was 24.8 (range: 15-36) weeks. The mean 3D-CT imaging period was 31.1 (range: 24-38) weeks' gestation, which is consistent with the period when CT testing is generally performed for prenatal diagnosis (approximately 30 weeks' gestation). Patient characteristics are presented in Table 2.

\section{Classification of fetal skeletal dysplasia}

Prenatal imaging data, postnatal findings, and pre- and postnatal diagnosis are presented in Table 3. The specific postnatal diagnoses were as follows: osteogenesis imperfecta (OI, $n=3$ ), thanatophoric dysplasia (TD, $n=$ 2 ), achondroplasia/hypochondroplasia $(\mathrm{ACH} / \mathrm{HCH}, n=$ 6), hypophosphatasia (HPP, $n=2$ ), campomelic dysplasia $(\mathrm{CD}, n=2)$, Desbuquois dysplasia $(n=1)$, and Creveld syndrome $(n=1)$. The two infants with HPP were siblings.

Sixteen infants (94.1\%) were diagnosed both prenatally and postnatally with FSD. The pre- and post-natal diagnoses differed in one infant who was diagnosed with OI prenatally but with $\mathrm{CD}$ postnatally. In this case, prenatal findings by 3D-CT were long bone shortening and mild curvature with scapular hypoplasia (Fig. 1), therefore, we diagnosed "OI" prenatally. However, we diagnosed "CD" in the postnatal period because we identified ambiguous genitalia and facial dysmorphia.

\section{Lethality}

Of the five fetuses with poor prognoses, one had OI, two had TD, and two had HPP. One of the fetuses with HPP suffered intrauterine fetal death at 27 weeks' gestation, while the remaining four infants died within two days of

Table 2 Characteristics of 17 infants with FSD

\begin{tabular}{|c|c|c|c|c|c|c|c|}
\hline Infant & $\begin{array}{l}\text { Maternal age } \\
\text { (years) }\end{array}$ & $\begin{array}{l}\text { GA at the first finding } \\
\text { of FSD (weeks) }\end{array}$ & $\begin{array}{l}\text { GA at 3D-CT } \\
\text { (weeks) }\end{array}$ & $\begin{array}{l}\text { GA at delivery } \\
\text { (weeks) }\end{array}$ & Delivery mode & Birth weight (g) & Prognosis \\
\hline 1 & 33 & 36 & 36 & 38 & CS & 2599 & alive \\
\hline 2 & 20 & 27 & 27 & 34 & CS & 2243 & alive \\
\hline 3 & 30 & 30 & 30 & 36 & $\mathrm{BE}$ & 1587 & 1 day \\
\hline 4 & 38 & 15 & 28 & 37 & CS (breech) & 2169 & 3 days \\
\hline 5 & 27 & 24 & 24 & 37 & VD & 2233 & 2 days \\
\hline 6 & 30 & 24 & 28 & 37 & CS & 2924 & alive \\
\hline 7 & 34 & 29 & 33 & 38 & VD & 3400 & alive \\
\hline 8 & 40 & 25 & 33 & 38 & VD & 2621 & alive \\
\hline 9 & 29 & 22 & 31 & 38 & CS (repeat) & 2250 & alive \\
\hline 10 & 41 & 27 & 31 & 38 & CS (NRFS) & 2080 & alive \\
\hline 11 & 29 & 33 & 35 & 38 & VD & 2496 & alive \\
\hline 12 & 30 & 34 & 38 & 39 & VD & 2676 & alive \\
\hline 13 & 39 & 17 & 35 & 37 & CS & 2569 & alive \\
\hline 14 & 39 & 30 & 27 & 39 & CS (repeat) & 1843 & alive \\
\hline 15 & 38 & 18 & 36 & 37 & CS (breech) & 2866 & alive \\
\hline 16 & 25 & 16 & 27 & 27 & VD & - & IUFD \\
\hline 17 & 26 & 15 & 28 & 38 & CS (breech) & 1710 & 1 day \\
\hline
\end{tabular}

$B E$ breech extraction, CS: cesarean section, GA gestational age, IUFD intrauterine fetal death, NRFS non-reassuring fetal status, FSD fetal skeletal dysplasia, VD vaginal delivery 
Table 3 Comparison between pre- and postnatal findings and diagnosis

\begin{tabular}{|c|c|c|c|c|}
\hline \multirow[t]{2}{*}{ Infant } & \multicolumn{2}{|l|}{ Prenatal } & \multicolumn{2}{|l|}{ Postnatal } \\
\hline & findings & diagnosis & findings & diagnosis \\
\hline 1 & $\begin{array}{l}\text { Shortening and bowing of long bones, Fractures of } \\
\text { femur and ribs }\end{array}$ & $\mathrm{Ol}$ & $\begin{array}{l}\text { Shortening and bowing of long bones, Fractures of } \\
\text { femur and ribs }\end{array}$ & $\mathrm{Ol}$ \\
\hline 2 & Shortening and bowing of long bones, hydramnios & $\mathrm{Ol}$ & Shortening and fractures of long bones & $\mathrm{Ol}$ \\
\hline 3 & $\begin{array}{l}\text { Shortening and bowing of long bones, Narrow } \\
\text { thorax, Megalencephaly }\end{array}$ & Ol & $\begin{array}{l}\text { Shortening and bowing of long bones, Rib fractures, } \\
\text { Narrow thorax, Facial dysmorphy }\end{array}$ & $\mathrm{Ol}$ \\
\hline 4 & $\begin{array}{l}\text { Shortening of long bones, Narrow thorax, } \\
\text { Megalencephaly }\end{array}$ & TD & $\begin{array}{l}\text { Rhyzomelic shortening of long bones, Bowing of long } \\
\text { bones, Narrow thorax, Megalencephaly, Platyspondylia }\end{array}$ & TD \\
\hline 5 & $\begin{array}{l}\text { Shortening and bowing of long bones Long bones } \\
\text { fractures Narrow thorax, Megalencephaly } \\
\text { Hydramnios }\end{array}$ & TD & $\begin{array}{l}\text { Shortening and bowing of long bones, Megalencephaly, } \\
\text { Frontal bossing, Narrow thorax, Platyspondylia, Trident } \\
\text { hand }\end{array}$ & TD \\
\hline 6 & Shortening of long bones, Narrow thorax & $\mathrm{ACH}$ or $\mathrm{HCH}$ & Shortening of long bones, Narrow thorax & $\mathrm{ACH}$ \\
\hline 7 & Shortening of long bones, Narrow thorax & $\mathrm{ACH}$ & Shortening of long bones, Narrow thorax & $\mathrm{ACH}$ \\
\hline 8 & $\begin{array}{l}\text { Shortening of long bones, Narrow thorax Trident } \\
\text { hand }\end{array}$ & $\mathrm{ACH}$ & $\begin{array}{l}\text { Shortening of long bones, Frontal bossing, Narrow thorax, } \\
\text { Trident hand }\end{array}$ & $\mathrm{ACH}$ \\
\hline 9 & Shortening of long bones, Narrow thorax & $\mathrm{ACH}$ & Shortening of long bones, Narrow thorax & $\mathrm{ACH}$ \\
\hline 10 & $\begin{array}{l}\text { Shortening of long bones, Narrow thorax, Trident } \\
\text { hand }\end{array}$ & $\mathrm{ACH}$ & $\begin{array}{l}\text { Shortening of long bones, Frontal bossing, Narrow thorax, } \\
\text { Trident hand, Facial dysmorphy of Down syndrome }\end{array}$ & $\begin{array}{l}\mathrm{ACH} \\
\text { Trisomy } 21\end{array}$ \\
\hline 11 & Shortening of long bones & $\mathrm{ACH}$ or $\mathrm{HCH}$ & Shortening of long bones, Frontal bossing & $\mathrm{HCH}$ \\
\hline 12 & $\begin{array}{l}\text { Shortening and bowing of long bones Hypoplastic } \\
\text { scapulae }\end{array}$ & $C D$ & $\begin{array}{l}\text { Shortening and bowing of long bones, Hypoplastic } \\
\text { scapulae }\end{array}$ & $C D$ \\
\hline 13 & $\begin{array}{l}\text { Shortening and bowing of long bones Mild } \\
\text { curvature with scapular hypoplasia Club feet }\end{array}$ & Ol & $\begin{array}{l}\text { Bowing of long bones, Club feet, Hypoplastic scapulae, } \\
\text { Rib fractures, Ambiguous genitalia, Facial dysmorphy }\end{array}$ & $C D$ \\
\hline 14 & $\begin{array}{l}\text { Dislocation of elbow and knee, Club feet Radioulnar } \\
\text { synostosis }\end{array}$ & $\begin{array}{l}\text { Desbuquois } \\
\text { disorder }\end{array}$ & $\begin{array}{l}\text { Dislocation of shoulder, elbow, Articulation coxae and } \\
\text { knee, Facial dysmorphy, Scoliosis, brevicollis }\end{array}$ & $\begin{array}{l}\text { Desbuquois } \\
\text { disorder }\end{array}$ \\
\hline 15 & $\begin{array}{l}\text { Shortening of long bones Hyperdactylia CHD } \\
\text { (AVSD, single atrium) }\end{array}$ & $\begin{array}{l}\text { Elis-van } \\
\text { Creveld } \\
\text { syndrome }\end{array}$ & $\begin{array}{l}\text { Shortening of long bones, Narrow thorax, Hyperdactylia, } \\
\text { CHD (AVSD, single atrium) }\end{array}$ & $\begin{array}{l}\text { Elis-van } \\
\text { Creveld } \\
\text { syndrome }\end{array}$ \\
\hline 16 & Shortening of long bones, Narrow thorax & HPP & - & $\mathrm{HPP}$ \\
\hline 17 & $\begin{array}{l}\text { Shortening of long bones, Narrow thorax, } \\
\text { hydramnios }\end{array}$ & HPP & $\begin{array}{l}\text { Shortening of long bones, Narrow thorax, Hypoplasia of } \\
\text { lung, Low levels of serum ALP }\end{array}$ & HPP \\
\hline
\end{tabular}

$A C H$ achondroplasia, $A V S D$ atrial ventricular septal defect, $C D$ campomelic dysplasia, $C H D$ congenital heart disease, $H C H$ hypochondroplasia, $H P P$ hypophosphatasia, Ol osteogenesis imperfecta, TD thanatophoric dysplasia

birth. We identified lethality in the prenatal period in all five fetuses.

\section{Trisomy 21 and achondroplasia}

Infant 8 was diagnosed prenatally with $\mathrm{ACH}$ based on ultrasound findings of shortened long bones, a narrow thorax, and a trident hand (Fig. 2). After birth, the characteristic trisomy 21 facial features were noted, and the results of chromosomal testing (G-band; 47, XY, + 21) confirmed trisomy 21. FGFR3 genetic analysis also indicated a G1193A mutation in G380, indicating that the infant also had $\mathrm{ACH}$.

\section{Postnatal genetic testing}

Genetic testing was performed in 11 infants (number; $1-$ $2,6-8,10,13-17)$.

In infant 12, we identified dislocation of the knee and elbow, as well as clubfeet, through sonography and 3D-
CT, leading us to suspect Desbuquois dysplasia (Fig. 3). Postnatal genetic testing confirmed our suspicion of Desbuquois dysplasia (type 1) due to a mutation of the 613,165 calcium-activated nucleotidase 1 (CANT1) gene.

The two infants with HPP (infants 14 and 15) had the same parents. Ultrasonography at 18 weeks' gestation in the first child revealed marked long bone shortening and a soft, deformed skull, which was suggestive of fetal HPP. Therefore, we measured maternal alkaline phosphatase (ALP) levels, which were low. At 27 weeks' gestation, the child suffered an intrauterine fetal death. After the child was stillborn, autopsy imaging was performed. The CT images also indicated a likely diagnosis of HPP. Genetic testing of the placental tissue revealed a compound heterozygote with mutations in two tissue-nonspecific alkaline phosphatase genes ( $A L P L$; p.K224E, c.1559delT), and confirmed our diagnosis of HPP. The parents' second child exhibited severe 


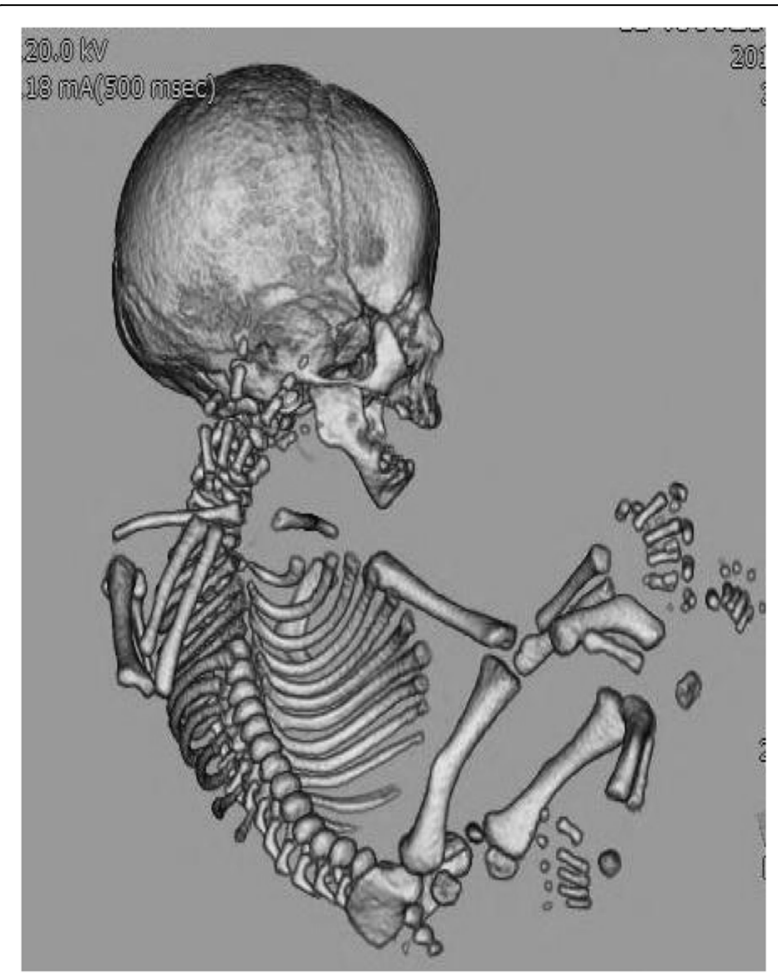

Fig. 1 Fetal 3-dimensional computed tomography imaging of Infant 13: A case of campomelic dysplasia with a postnatal diagnosis that was different from the prenatal diagnosis

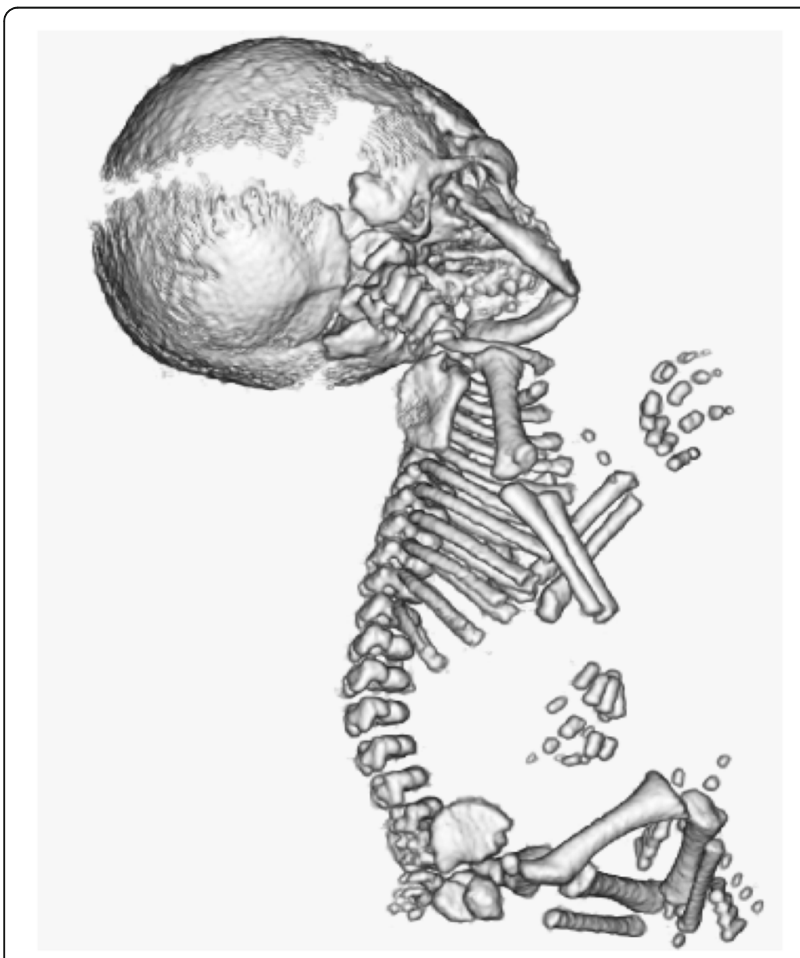

Fig. 2 Fetal 3-dimensional computed tomography imaging of Infant 8: A case of achondroplasia with trisomy 21

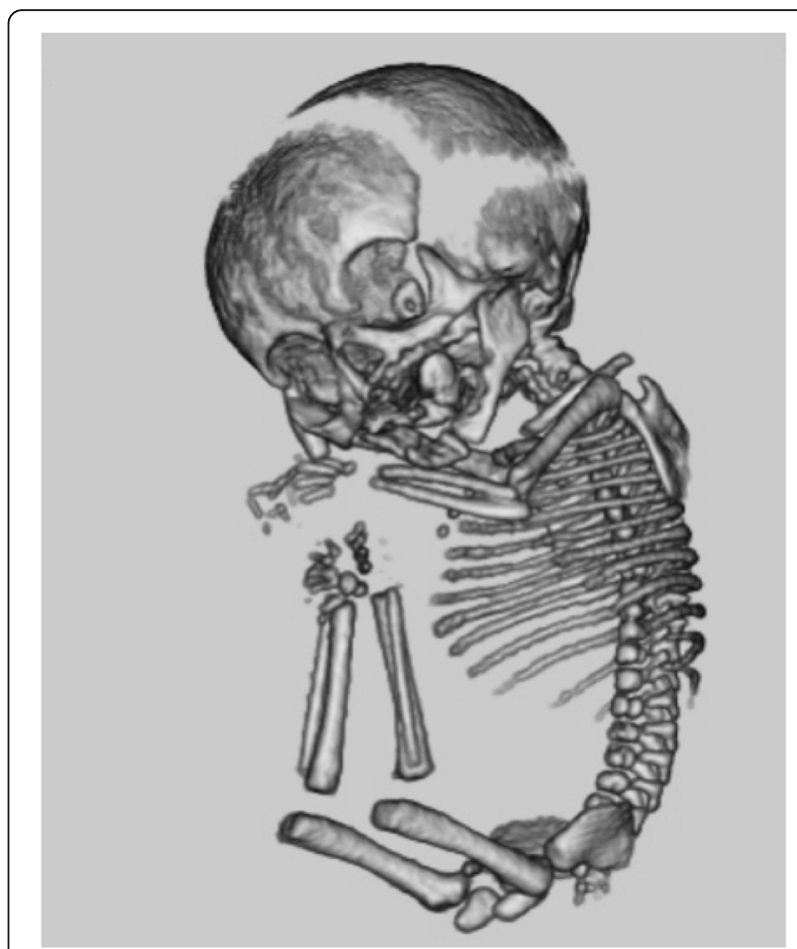

Fig. 3 Fetal 3-dimensional computed tomography imaging of Infant 14: A case of Desbuquois dysplasia

shortening of all four limbs at 15 weeks' gestation, with 3D-CT revealing findings typical of severe prenatal HPP (Fig. 4), with hardly any ossification. At 38 weeks' gestation, the infant was delivered via cesarean section but suffered neonatal death at 1 day of age.

\section{Discussion}

The first-line method for the prenatal diagnosis of skeletal dysplasia is typically sonographic imaging; however, it is difficult to perform a classification of FSD. Although 3D-CT may be a valuable imaging tool complementary to ultrasonography for the diagnosis and classification of FSD, it is necessary to select the appropriate sonography settings to minimize the degree of fetal irradiation without compromising image quality $[6,7]$. Fetal radiation exposure should be concerned with fetal CT. The dose of 3D-CT was a mean $\mathrm{CTDI}_{\mathrm{vol}}$ of $3.5 \mathrm{mGy}$ (range: 1.9-4.9 mGy); this is "low-dose" fetal CT, which has been reported in 2013: a mean $\mathrm{CTDI}_{\mathrm{vol}}$ of $2.2 \mathrm{mGy}$ [4] and $4.2 \mathrm{mGy}$ [8]. In 2008, the International Commission on Radiological Protection recommended that in utero exposure to less than $100 \mathrm{mGy}$ would be of no practical significance and poses a lifetime cancer risk [9]. A mean $\mathrm{CTDI}_{\mathrm{vol}}$ of $2.9 \mathrm{mGy}$ is far below $100 \mathrm{mGy}$.

MRI may be useful to differentiate between FSD and other limb malformations $[10,11]$. Spatial recognition is easy in fetal MRI, as the bone marrow and soft tissue are clearly identified. However, it may not be suitable for 


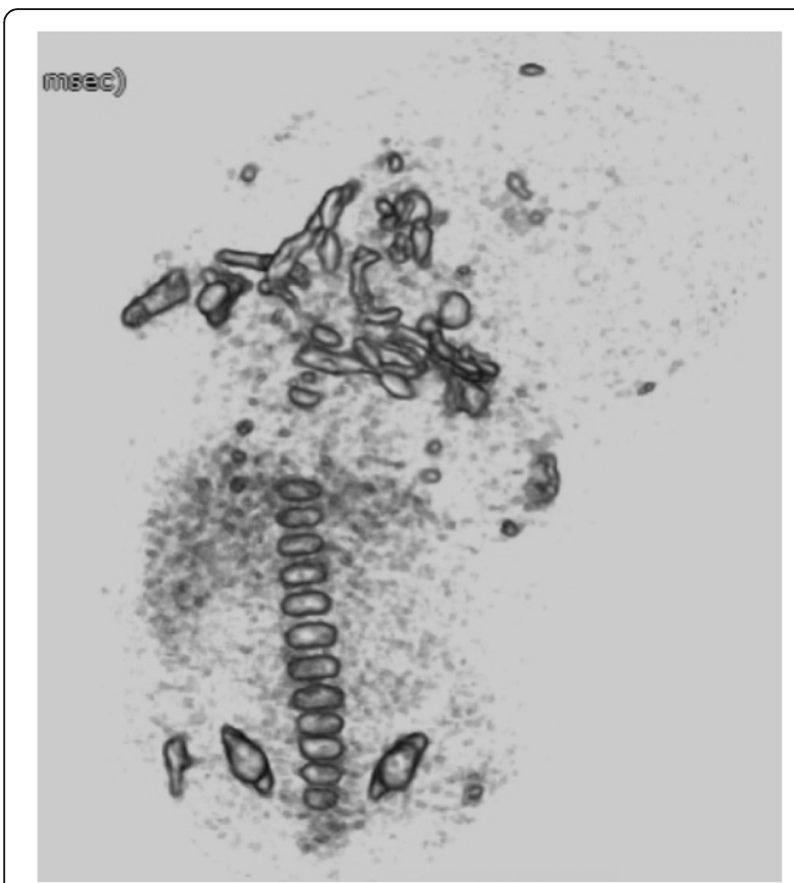

Fig. 4 Fetal 3-dimensional computed tomography imaging of Infant 17: A case of hypophosphatasia

identifying the bone cortex. CT uses ionizing radiation to produce an X-ray image which is similar to that produced by plain radiography. Radiography has traditionally been used as a diagnostic imaging method for skeletal system diseases, and the experience can be reflected in diagnostic $\mathrm{CT}$ imaging using X-ray characteristics of skeletal system diseases. Observations from a $360^{\circ}$ view are made possible by obtaining $3 \mathrm{D}$ images, and the diagnostic accuracy may be increased by observing from the direction with greatest visibility. Furthermore, fetuses in utero often have their limbs and spines flexed. Therefore, image reconstruction may be enabled by eliminating these limbs from view or selecting only the section to be observed by trimming, which then provides meaningful images for diagnosis [12]. Using low-dose 3D-CT imaging, we can create an MIP image of a point that we should focus on. The depiction of the details for abnormal points is made clearer by adding the MIP images; therefore, it helps in making a diagnosis of FSD.

Fetal bone 3D-CT (as an auxiliary test for ultrasound examinations) provides detailed information on systemic skeletal structure when performed at 26 weeks' gestation onward. The detection of abnormal findings outside the skeletal system on sonography can greatly affect the diagnosis $[8,13]$. For a diagnosis of FSD, both sonography and $3 \mathrm{D}-\mathrm{CT}$ appear to be useful methods. In some cases, it can be difficult to differentiate skeletal dysplasia from a chromosomal abnormality. Of the 19 infants that underwent 3D-CT in our study, only one was suspected of having a chromosomal abnormality. In this case, skeletal dysplasia was suspected based on ultrasonography findings, but the results of 3D-CT suggested trisomy 21 . Postnatal chromosomal testing was performed, resulting in a final diagnosis of trisomy 21 and the exclusion of this infant from the study. Some cases can be complicated, with concomitant skeletal dysplasia and a chromosome aberration. In particular, cases with combined $\mathrm{ACH}$ and trisomy 21 have been reported [14, 15]. $\mathrm{ACH}$ is included as a type of dysplasia in the group of FGFR3 abnormalities, where growing parts become hypoplastic due to endochondral ossification. This can be difficult to differentiate from trisomy $21[14,15]$. In 2001 [16] and 2014 [17], it was reported that femoral shortening during the second trimester is associated with a high relative risk of chromosomal abnormalities, particularly trisomy 21 . If fetal femoral shortening is observed, it is important to consider the possibility of conditions such as chromosomal abnormalities, fetal growth restriction, and various other anomalies. Attention should also be paid to the presence of abnormal findings outside of the skeletal system (e.g., abnormalities in cardiac structure, the nervous/gastrointestinal system, and facial features) to reach a differential diagnosis. When making a prenatal diagnosis, it is important to bear in mind that cases of concomitant skeletal dysplasia and chromosomal abnormalities are possible, albeit rare.

Desbuquois dysplasia is a severe autosomal recessive disorder that belongs to the multiple dislocation group [18]. It is characterized by shortened long bones, joint laxity, pre- and postnatal growth retardation, and progressive scoliosis. In the case of infant 12, the mother's first child also had skeletal dysplasia (congenital dislocation of the knees), which was identified after birth. Although this child had been diagnosed with Larsen syndrome, it had neither been identified prenatally by sonography/3D-CT nor confirmed via postnatal genetic testing. The mother's second child (infant 12), in contrast, underwent a prenatal ultrasound examination and 3D-CT and was diagnosed with Desbuquois dysplasia, rather than Larsen syndrome. Postnatal genetic testing led to a definitive diagnosis of Desbuquois dysplasia (type 1), which is due to a mutation in the CANT1 gene $[19,20]$. It is difficult to distinguish Desbuquois dysplasia and Larsen syndrome based on clinical manifestations. In the case of infant 12 , it was demonstrated that an accurate prenatal diagnosis using an ultrasound examination and 3D-CT imaging was important to achieve a definitive diagnosis via postnatal molecular evaluation.

HPP is a condition in which tissue non-specific ALP loss or decrease causes abnormal bone and tooth 
mineralization [21]. Many cases of HPP are inherited in an autosomal recessive, rather than an autosomal dominant manner. HPP can be classified into the following six clinical forms, which vary based on severity [22]: 1) perinatal severe, 2) perinatal benign, 3) infantile, 4) childhood, 5) adult, and 6) odontohypophosphatasia. If parents have a child with HPP, they should be given genetic counseling with respect to future pregnancies, and the couple can decide whether to undergo carrier detection testing. If both the mother and father are carriers, the child has a $25 \%$ probability of being homozygous. Our fatal perinatal case appeared to be a severe one. The symptoms of perinatal cases appear early, resulting in intrauterine fetal death [23], stillbirth, or neonatal death. If we have a diagnosis of HPP in the prenatal period, we are able to start the enzyme replacement therapy promptly.

Compared to normal fetuses, those with FSD are more likely to be in an abnormal fetal position owing to differences in physique, restricted posture, limited joint range of motion, and fractures [24]. In cases of OI, it can be difficult to prevent intrauterine fractures as they can be caused by fetal movement (Fig. 5). Studies have shown that, in cases of OI, performing a cesarean delivery does not increase the frequency of fetal bone fractures compared to vaginal delivery [25]. Moreover, in cases of the

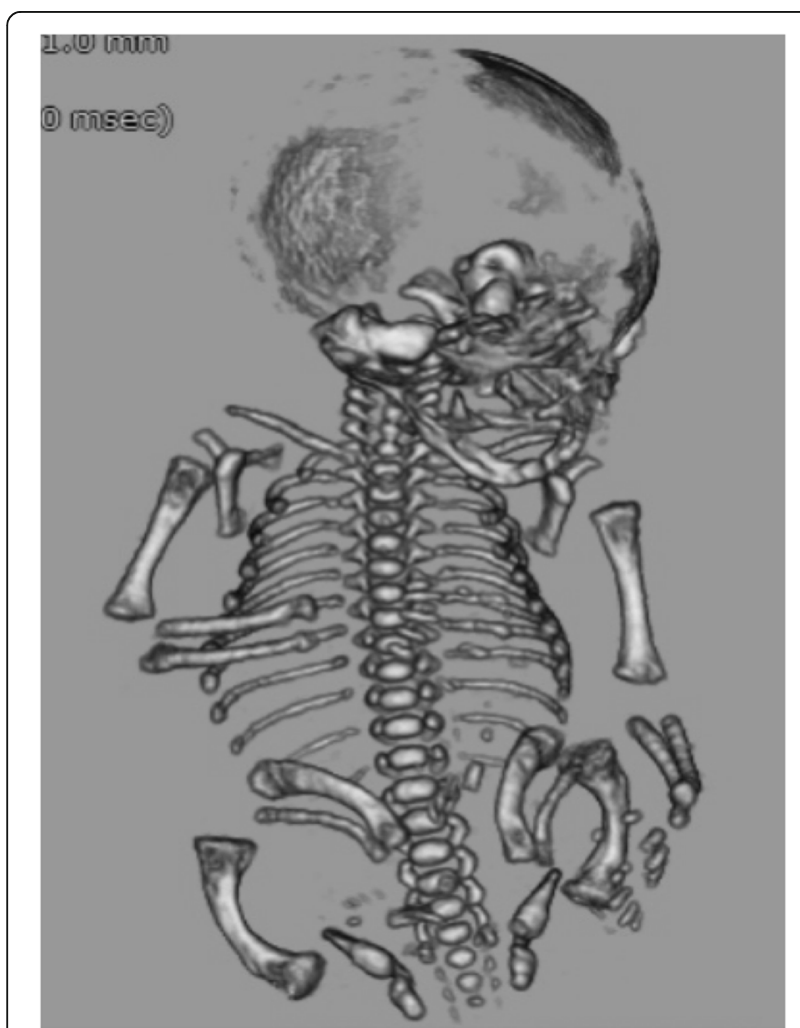

Fig. 5 Fetal 3-dimensional computed tomography imaging of Infant 2: A case of osteogenesis imperfecta lethal type of OI, fetal survival does not appear to be affected by delivery mode (cesarean vs. vaginal delivery). For other types of skeletal dysplasias, the mode of delivery is often selected based on whether the condition is lethal. When the disease is diagnosed as lethal, vaginal delivery may be selected even if the fetus is breech. However, in cases with marked head enlargement, a cesarean section is required regardless of whether the case is fatal, owing to the potential difficulty in passing through the mother's pelvis. Before delivery, the parents, obstetricians, pediatricians, and orthopedic surgeons need to discuss the plan for the resuscitation of the infant after birth. The classification by imaging of 3D-CT is imperative to decide on the delivery mode and treatment policy for the infant, for example, whether to perform endotracheal intubation, or to surgically treat the infants. Reliable prenatal diagnosis is required to determine whether the case is fetal and its degree of severity.

When considering the risk of radiation exposure, CT examination has not historically been the preferred method for pregnant women. However, in recent years, high-quality images adequate for diagnosis have been displayed by low-dose 3D-CT, reducing the level of radiation to which the mother and fetus are exposed. The limitation of this study is the relatively small sample size. Future studies should include a larger sample size to improve the power of the results. Continuation of this study is important to improve the diagnostic accuracy of fetal skeletal dysplasia.

\section{Conclusions}

3D-CT is a valuable tool for augmenting ultrasound examinations in the diagnosis of FSD. While improving the diagnostic tool of sonography is important in cases of suspected FSD, 3D-CT imaging is indispensable for a diagnosis and a classification, enabling better planning for resuscitation of the infant after birth.

\section{Abbreviations \\ FSD: Fetal skeletal dysplasia; 3D-CT: Three-dimensional computed tomography; MRI: Magnetic resonance imaging; Ol: Osteogenesis imperfecta; TD: Thanatophoric dysplasia; ACH/HCH: Achondroplasia/hypochondroplasia; HPP: Hypophosphatasia; CD: Campomelic dysplasia; CANT1: Calcium- activated nucleotidase 1; ALP: Alkaline phosphatase}

\section{Acknowledgments}

We thank the patients and their families involved in this study. We would like to thank Editage (www.editage.com) for English language editing.

\section{Authors' contributions}

The author contributions are as follows: MW conceived and designed the study, wrote the protocol manuscript, and analyzed and interpreted the data. FI, YT, AM, and TM collected the study data. JK provided guidance regarding the study design and ethical approval. All authors read and approved the final manuscript.

\section{Funding}

This research received no specific grant from any funding agency in the public, commercial or not-for-profit sectors. 


\section{Availability of data and materials}

The datasets generated and/or analyzed during this study are available in the University Hospital Medical Information Network (UMIN). (URL: https:// upload.umin.ac.jp/cgi-open-bin/ctr_e/ctr_view.cgi?recptno=R000039610).

\section{Ethics approval and consent to participate}

The institutional review boards of Kyoto Prefectural University of Medicine (ERB-C-991) and all the participating hospitals approved the protocol. Written informed consent was obtained from all patients before registration in accordance with the Declaration of Helsinki. The results of the study will be disseminated via publication in peer-reviewed journals.

\section{Consent for publication}

Not applicable.

\section{Competing interests}

The authors declare that they have no competing interests.

Received: 18 June 2020 Accepted: 20 September 2020

Published online: 08 October 2020

\section{References}

1. Chen C, Jiang $Y, X u C$, Liu X, Hu L, Xiang Y, et al. Skeleton genetics: a comprehensive database for genes and mutations related to genetic skeletal disorders. Database (Oxford). 2016;2016:baw127.

2. Bonafe L, Comier-Daire V, Hall C, Lachman R, Mortier G, Mundlos S, et al. Nosology and classification of genetic skeletal disorders: 2015 revision. Am J Med Genet A. 2015;167A:2869-92.

3. Krakow D, Lachman RS, Rimoin DL. Guidelines for the prenatal diagnosis of fetal skeletal dysplasias. Genet Med. 2009;11:127-33.

4. Doray B, Favre R, Viville B, Langer B, Dreyfus M, Stoll C. Prenatal sonographic diagnosis of skeletal dysplasias. A report of 47 cases. Ann Genet. 2000:43:163-9.

5. Ruano R, Molhi M, Roume J, Ville Y. Prenatal diagnosis of fetal skeletal dysplasias by combining two-dimensional and three-dimensional ultrasound and intrauterine three-dimensional helical computer tomography. Ultrasound Obstet Gynecol. 2004:24:134-40.

6. Macé G, Sonigo P, Cormier-Daire V, Aubry MC, Martinovic J, Elie C, et al. Three-dimensional helical computed tomography in prenatal diagnosis of fetal dysplasia. Ultrasound Obstet Gynecol. 2013;42:161-8.

7. Adler-Levy Y, Yagel S, Nadjari M, Bar-ziv Y, Simanovsky N, Hiller N. Use of low dose computed tomography with 3D reconstructions for the prenatal evaluation of suspected skeletal dysplasia. Isr Med Assoc J. 2015;17:42-6.

8. Victoria T, Epelman M, Coleman BG, Horii S, Oliver ER, Mahboubi S, et al. Low-dose fetal CT in the prenatal evaluation of skeletal dysplasias and other severe skeletal abnormalities. AJR Am Roentgenol. 2013;200:989-1000.

9. Wrixon AD. New ICRP recommendations. J Radiol Prot. 2008;28:161-8.

10. Alrabai HM, Farr A, Bettelheim D, Weber M, Farr S. Prenatal diagnosis of congenital upper limb differences: a current concept review. I Mtatern Fetal Neonatal Med. 2017:30:2557-63.

11. Farr A, Wachutka E, Bettelheiom D, Windsperger K. Farr S/ prenatal putcomes of infants with congenital limb malformations: an observational study from a tertiary referral center in Central Europe. BMC Pregnancy Child. 2020;20:35.

12. Cassart M, Massez A, Cos T, Tecco L, Thomas D, Van Regemorter N, et al. Contribution of three-dimensional computed tomography in the assessment of fetal skeletal dysplasia. Ultrasound Obstet Gynecol. 2007; 29:537-43.

13. Kaga A, Murotsuki J, Kamimura M, Kimura M, Saito-Hakoda A, Kanno J, et al. Association of achondroplasia with Down syndrome: difficulty in prenatal diagnosis by sonographic and 3-D helical computed tomographic analysis. Congenit Anom (Kyoto). 2015;55:116-20.

14. de Azevedo Moreira LM, Matos MA, Schiper PP, Carvalho AF, Gomes IC, Rolemberg JC, et al. Co-occurrence of achondroplasia and Down syndrome: genotype/phenotype association. Birth Defects Res A Clin Mol Teratol. 2010; 88:228-31

15. Smith-Bindman R, Hosmer W, Feldstein VA, Deeks JJ, Goldberg JD. Secondtrimester ultrasound to detect fetuses with Down syndrome: a metaanalysis. JAMA. 2001;285:1044-55.

16. Mathiesen JM, Aksglaede L, Skibsted L, Petersen OB, Tabor A. Danish fetal medicine study group. J Ultrasound Obstet Gynecol. 2014;44:160-5.
17. Huber C, Oulès B, Bertoli $M$, Chami $M$, Fradin $M$, Alanay $Y$, et al. Identification of CANT1 mutations in Desbuquois dysplasia. Am J Hum Genet. 2009;85:706-10.

18. Inoue S, Ishii A, Shirotani G, Tsutsumi M, Ohta E, Nakamura M, et al. Case of Desbuquois dysplasia type 1: potentially lethal skeletal dysplasia. Pediatr Int. 2014;56:26-9.

19. Laccone F, Schoner K, Krabichler B, Kluge B, Schwerdtfeger R, Schulze B, et al. Desbuquois dysplasia type 1 and fetal hydrops due to novel mutations in the CANT1 gene. Eur J Hum Genet. 2011;19:1133-7.

20. Suzumori N, Mornet E, Mizutani E, Obayashi S, Ozaki Y, Sugiura-Ogasawara M. Prenatal diagnosis of familial lethal hypophosphatasia using imaging, blood enzyme levels, chorionic villus sampling and archived fetal tissue. J Obstet Gynaecol Res. 2011;37:1470-3.

21. Nakamura-Utsunomiya A, Okada S, Hara K, Miyagawa S, Takeda K, Fukuhara $R$, et al. Clinical characteristics of perinatal lethal hypophosphatasia: a report of 6 cases. Clin Pediatr Endocrinol. 2010;19:7-13.

22. Tongsong T, Pongsatha S. Early prenatal sonographic diagnosis of congenital hypophosphatasia. Ultrasound Obstet Gynecol. 2000;15:52-5

23. Van Dijk FS, Sillence DO. Osteogenesis imperfecta: clinical diagnosis, nomenclature and severity assessment. Am J Med Genet A. 2014;164A: 1470-81.

24. Bellur S, Jain M, Cuthbertson D, Krakow D, Shapiro JR, Steiner RD, et al. Delivery by cesarean section is not associated with decreased at-birth fracture rates in osteogenesis imperfecta. Genet Med. 2016:18:570-6.

25. Jain V, Sen B. Campomelic dysplasia. J Pediatr Orthop B. 2014;23:485-8.

\section{Publisher's Note}

Springer Nature remains neutral with regard to jurisdictional claims in published maps and institutional affiliations.

Ready to submit your research? Choose BMC and benefit from:

- fast, convenient online submission

- thorough peer review by experienced researchers in your field

- rapid publication on acceptance

- support for research data, including large and complex data types

- gold Open Access which fosters wider collaboration and increased citations

- maximum visibility for your research: over $100 \mathrm{M}$ website views per year

At $\mathrm{BMC}$, research is always in progress.

Learn more biomedcentral.com/submissions 